\title{
Knowledge, Attitude and Practice of Postgraduate Dental Students Towards Plagiarism in Maharashtra State, India: A Cross-Sectional Survey
}

\author{
Deshmukh Manjiri ${ }^{1}$, Dodamani Arun ${ }^{2}$, Karibasappa GN ${ }^{3}$, Khairnar Mahesh ${ }^{4 *}$, Naik Rahul ${ }^{5}$ \\ ${ }^{I}$ Dept. of Public Health Dentistry, Swargiya Dadasaheb Kalmegh Smruti Dental College \& Hospital, Nagpur, \\ Maharashtra, India \\ ${ }^{2}$ Department of Public Health Dentistry, A.C.P.M. Dental College \& Hospital, Dhule, Maharashtra, India \\ ${ }^{3}$ Department of Public Health Dentistry, Dr. D. Y. Patil Dental School, Pune, Maharashtra, India \\ ${ }^{4}$ Department of Public Health Dentistry, Bharati Vidyapeeth Deemed University Dental College \& Hospital, \\ Sangli, Maharashtra, India \\ ${ }^{5}$ Department of Public Health Dentistry, A.C.P.M. Dental College \& Hospital, Dhule, Maharashtra, India \\ *Corresponding Author: Khairnar Mahesh, Department of Public Health Dentistry, Bharati Vidyapeeth \\ Deemed University Dental College \& Hospital, Sangli, Maharashtra, India, Email: kmahesh222@ \\ gmail.com
}

\begin{abstract}
Objective: Of late, issues of scientific integrity have been on the rise in dentistry. Hence, the present study aimed to assess the knowledge, attitude and practices amongst the MDS students in Maharashtra towards plagiarism.
\end{abstract}

Methods: A questionnaire-based cross-sectional survey was conducted on dental postgraduate or MDS [Master of Dental Surgery] students in Maharashtra. A self-designed, closed ended questionnaire consisting of 18 questions was prepared and it was circulated amongst 412 MDS students through an online survey portal out of which 256 students responded. The data obtained was subjected to appropriate statistical tests.

Results: Results showed that $3^{\text {rd }}$ year MDS [III MDS] students had more knowledge regarding plagiarism than $1^{\text {st }}$ year MDS [I MDS] \& $2^{\text {nd }}$ year MDS [II MDS] students [p<0.05]; however, there was no significant difference in attitude and practice of plagiarism in between I, II \& III MDS students. However, $21.8 \%$ students agreed that they had practiced plagiarism at-least once.

Conclusion: Plagiarism is a major issue that threatens our search for truth in science. Hence, students should be encouraged and motivated to adopt value-based scientific research and practice of genuine publications.

Keywords: Plagiarism; Publication Ethics; Research Ethics; Research Integrity

\section{INTRODUCTION}

Science is the search for truth and the foundation of science should be honesty, integrity and truthfulness. Due to academic competitiveness and the urge to succeed instantly using shortcuts, the 'stealing' of literature in the scientific fields is alarmingly increasing. Research misconduct has been around the corner for as long as humans have produced the work of art and science. Perhaps the most comprehensive and legally-tenable definition on research misconduct comes from the United States Public Health Service [USPHS]: "Fabrication, falsification, or plagiarism, in proposing, performing, or reviewing research, or in reporting research results. It includes: [a] fabrication is making up data or results and recording or reporting them; [b] Falsification is manipulating research materials, equipment, or processes, or changing or omitting data or results such that the research is not accurately represented in the research record; [c] Plagiarism is the appropriation of another person's ideas, processes, results, or words without giving appropriate credit" [1].

Perhaps, the most widely recognized unethical practice in medical writing is plagiarism [2]. Plagiarism is defined as unauthorized 
appropriation of another's work, ideas, methods, results or words without acknowledging the source and original author [3].Although some dictionaries treat the etymology of the word plagiarism as coming from the Latin, plagiarius [hijacker or kidnapper], Skandalakis \& Mirilas [2004] argue that the word originated from the Greek plagios [obliquity, in the sense that whom presents a skewed moral] [4]. The meaning of the word 'plagiarize' from 'The MerriamWebster Online Dictionary,' defines it as - to steal and pass off [the ideas or words of another] as one's own; to use [another's production] without crediting the source; to commit literary theft; to present as new and original an idea or product derived from an existing source[5].

Plagiarism seems to have increased with the availability of Internet access, simply because so much matter is easily available and it is so easy to copy matter [6]. This issue has been plaguing the world for centuries but the internet and subsequent proliferation of information has made the problem far more serious than before. Plagiarism constitutes an action where authors use matter from different publications, usually without referencing them, and try to pass it off as their own work [6].This bane of plagiarism, in simple words, is an act of fraud [5] and more importantly, it is a 'neglected fraud'. It involves both stealing someone else's work and lying about it afterwards ${ }^{5}$ and stealing by anyone in any form should be punished. Thus, it is indeed a deplorable, lamentable and unethical act. But words like 'copying' and 'borrowing' can disguise and lower the seriousness of this serious scientific and academic offence.

Plagiarism begins very early in science [1]. It probably starts with the seminar presentations students make early during their professional studies. Most dissertations submitted by medical students are copied from previously published literature [2]. Some recent incidents of plagiarism in India like overlaps from another published review or publication of same articles in two different journals and [near lack of] action thereof underscores the deep rot that has set in [1]. Thus, it is clear that the plague of plagiarism has not spared the medical field too. Postgraduate students, being budding practitioners as well as novice researchers can be a common target as well as victim for plagiarism. But there is dearth of literature on the perception of PG students towards this pollutant of science. This provided an impetus to conduct the present study to assess the knowledge, attitude and practices of I, II \& III MDS students across Maharashtra towards Plagiarism.

\section{Methodology}

The present study was a cross-sectional survey conducted online through www.surveymonkey. com. The study protocol was approved by the Institutional Review Board and ethical clearance was obtained from the Institutional Ethical Committee of a private dental college in Maharashtra.

The study was conducted on dental postgraduate students [MDS students] studying in 10 dental institutes of Maharashtra state, India. Email addresses of post-graduate students were obtained for the study purpose. A list of 412 email addresses of the post-graduate students was prepared to whom the links for the online questionnaire were sent.

A self-designed questionnaire consisting of 18 closed-ended questions was prepared. It comprised of 6 knowledge-related questions, 5 attitude-related questions and 7 practices-related questions. A pilot survey was conducted by selfadministering this questionnaire to 20 MDS students to check for the reliability. The required changes were made in the questionnaire after getting the responses and again it was administered to another 20 MDS students. The value of Cronbach's alpha coefficient for the knowledge and attitude questions was $0.71 \& 0.72$ which is considered as acceptable. Since each participant must have committed at least a case of plagiarism, assessment of the reliability for the practice questions was not performed.

The questionnaire was uploaded on the website www.surveymonkey.com. The web links were mailed to 412 MDS post-graduate students out of which 256 students responded. The responses were collected, compiled and tabulated in MSExcel sheet. The data was then subjected to statistical analysis at the 5\% significance level [P<0.05] using SPSS-16 to use Pearson's Chi Square Test and Kruskal Wallis test.

\section{RESUltS}

Out of 412 students approached, 256 responded [response rate of $62.13 \%$ ]. 8 responses were excluded owing to incompleteness. Thus, the responses of 248 MDS students were considered for analysis. Out of the 248 MDS students, 138 were males and 110 were females. 32 were I MDS students, 96 were II MDS and 120 were III MDS. 
Knowledge, Attitude and Practice of Postgraduate Dental Students Towards Plagiarism in Maharashtra State, India: A Cross-Sectional Survey

Table1. Distribution of MDS students in the survey

\begin{tabular}{|l|l|l|l|l|}
\hline Gender & I MDS & II MDS & III MDS & Total \\
\hline Male & $20[62.5 \%]$ & $52[54.2 \%]$ & $66[55.0 \%]$ & $138[55.6 \%]$ \\
\hline Female & $12[37.5 \%]$ & $44[45.8 \%]$ & $54[45.0 \%]$ & $110[44.4 \%]$ \\
\hline Total & $32[100.0 \%]$ & $96[100.0 \%]$ & $120[100.0 \%]$ & $248[100.0 \%]$ \\
\hline
\end{tabular}

Pearson's Chi Square Test showed that there was significant difference in the knowledge about plagiarism amongst I, II and III MDS students with III MDS students having significant higher knowledge about plagiarism

Table2. Comparison of Knowledge about Plagiarism amongst I, II and III year MDS students

\begin{tabular}{|c|c|c|c|c|c|c|}
\hline \multirow{2}{*}{$\begin{array}{l}\text { Sr. } \\
\text { No }\end{array}$} & \multirow[t]{2}{*}{ Knowledge: } & \multicolumn{4}{|c|}{ MDS [year] } & \multirow{2}{*}{$\begin{array}{l}\mathbf{P} \\
\text { Value }\end{array}$} \\
\hline & & $\begin{array}{l}\mathbf{I} \\
{[\mathrm{n}=32]}\end{array}$ & $\begin{array}{l}\text { II } \\
{[n=96]}\end{array}$ & $\begin{array}{l}\text { III } \\
{[n=120]}\end{array}$ & $\begin{array}{l}\text { Total } \\
{[n=248]}\end{array}$ & \\
\hline $\mathbf{1}$ & Know the meaning of the term "Plagiarism"? & $81.3 \%$ & $83.3 \%$ & $93.3 \%$ & $87.9 \%$ & $0.038 *$ \\
\hline 2 & $\begin{array}{l}\text { Aware of mandatory Dental Council of India point } \\
\text { system for scientific publications in academics }\end{array}$ & $68.8 \%$ & $66.7 \%$ & $81.7 \%$ & $74.2 \%$ & $0.033 *$ \\
\hline 3 & Plagiarism is an act of academic malpractice & $75 \%$ & $83.3 \%$ & $86.7 \%$ & $83.9 \%$ & 0.276 \\
\hline 4 & Plagiarism is a punishable offence & $43.8 \%$ & $37.5 \%$ & $60 \%$ & $49.2 \%$ & $0.004 *$ \\
\hline 5 & Softwares available to check plagiarism & $50 \%$ & $41.7 \%$ & $60 \%$ & $51.6 \%$ & $0.027 *$ \\
\hline 6 & Has adverse effect on the health of the community & $62.5 \%$ & $37.5 \%$ & $60 \%$ & $51.6 \%$ & $0.002 *$ \\
\hline
\end{tabular}

*significance at $p<0.05$

There was no significant difference in the attitudes towards plagiarism amongst I, II and III MDS students. The most common reason perceived by students for practicing plagiarism

Table3. Comparison of Attitude about Plagiarism amongst I, II and III year MDS students

\begin{tabular}{|c|c|c|c|c|c|c|}
\hline \multirow{2}{*}{$\begin{array}{l}\text { Sr. } \\
\text { No }\end{array}$} & \multirow[t]{2}{*}{ Attitudes } & \multicolumn{4}{|c|}{ MDS [year] } & \multirow{2}{*}{$\begin{array}{l}\mathbf{P} \\
\text { value }\end{array}$} \\
\hline & & $\begin{array}{l}I \\
{[n=32]}\end{array}$ & $\begin{array}{l}\text { II } \\
{[n=96]}\end{array}$ & $\begin{array}{l}\text { III } \\
{[n=120]}\end{array}$ & $\begin{array}{l}\text { Total } \\
{[\mathrm{n}=\mathbf{2 4 8}]}\end{array}$ & \\
\hline 1 & Lack of faculty members to address this issue & $87.5 \%$ & $79.2 \%$ & $78.3 \%$ & $79.8 \%$ & 0.506 \\
\hline 2 & Think plagiarism as sometimes a necessity & $37.5 \%$ & $58.3 \%$ & $56.7 \%$ & $54.8 \%$ & 0.104 \\
\hline 3 & $\begin{array}{l}\text { Think that short deadlines in academics as major } \\
\text { impetus }\end{array}$ & $56.3 \%$ & $85.4 \%$ & $86.7 \%$ & $82.3 \%$ & $<0.01$ \\
\hline 4 & $\begin{array}{l}\text { Reasons for Plagiarism:- } \\
\text { a. Lack of value-based education and morals } \\
\text { b.DCI requirements of publications } \\
\text { c. Inadequate knowledge of the art of writing } \\
\text { manuscripts } \\
\text { d. No regulations against plagiarism }\end{array}$ & $\begin{array}{l}25 \% \\
6.3 \% \\
62.5 \% \\
6.3 . \%\end{array}$ & $\begin{array}{l}27.1 \% \\
18.8 \% \\
39.6 \% \\
14.6 \%\end{array}$ & $\begin{array}{l}16.7 \% \\
13.3 \% \\
63.6 \% \\
6.7 \%\end{array}$ & $\begin{array}{l}21.8 \% \\
14.5 \% \\
54 \% \\
\\
9.7 \%\end{array}$ & NS \\
\hline 5 & Regulations should be laid down against plagiarism & $100 \%$ & $93.8 \%$ & $95 \%$ & $95.2 \%$ & 0.359 \\
\hline
\end{tabular}

* significance at $p<0.05 ;$ NS- Non significant

There was no significant difference in the practice of plagiarism amongst I, II and III MDS students. Only 50\% MDS students had published scientific article and maximum i.e. $71.7 \%$ were III MDS compared to I and II MDS

was found to be inadequate knowledge of the art of writing manuscripts, followed by lack of

value-based education and morals. 87.9\% MDS students knew about Plagiarism and maximum were III MDS i.e. $93.3 \%$ were having the knowledge.

as compared to I and II MDS students [p<0.05]. [p<0.01]. Out of 248 students, $21.8 \%$ of the students practiced plagiarism at least once. However, $81.5 \%$ students admitted that committing plagiarism would hurt their inner conscience.

Table4. Comparison of Practices about Plagiarism among I, II and III year MDS students

\begin{tabular}{|c|c|c|c|c|c|c|}
\hline \multirow{2}{*}{$\begin{array}{l}\text { Sr. } \\
\text { No }\end{array}$} & \multirow[t]{2}{*}{ Practices: } & \multicolumn{4}{|c|}{ MDS [year] } & \multirow{2}{*}{$\begin{array}{l}p \\
\text { value }\end{array}$} \\
\hline & & $\begin{array}{l}I \\
{[n=32]}\end{array}$ & $\begin{array}{l}\text { II } \\
{[n=96]}\end{array}$ & $\begin{array}{l}\text { III } \\
{[n=120]}\end{array}$ & $\begin{array}{l}\text { Total } \\
{[n=248]}\end{array}$ & \\
\hline 1 & Published your scientific article & $18.8 \%$ & $33.3 \%$ & $71.7 \%$ & $50 \%$ & $<0.01$ \\
\hline 2 & Knowingly practiced plagiarism even once & $12.5 \%$ & $22.9 \%$ & $23.3 \%$ & $21.8 \%$ & 0.394 \\
\hline 3 & Plagiarizing because you haven't been caught & $12.5 \%$ & $43.8 \%$ & $20.8 \%$ & $28.6 \%$ & $<0.01$ \\
\hline
\end{tabular}


Knowledge, Attitude and Practice of Postgraduate Dental Students Towards Plagiarism in Maharashtra State, India: A Cross-Sectional Survey

\begin{tabular}{|l|l|l|l|l|l|l|}
\hline & yet & & & & & \\
\hline $\mathbf{4}$ & Studying in a plagiarism-free environment & $43.8 \%$ & $29.2 \%$ & $30 \%$ & $31.5 \%$ & 0.273 \\
\hline $\mathbf{5}$ & Staff encourage plagiarism & $18.8 \%$ & $25 \%$ & $16.7 \%$ & $20.2 \%$ & 0.309 \\
\hline $\mathbf{6}$ & Plagiarism hurt your inner conscience & $87.5 \%$ & $81.3 \%$ & $80 \%$ & $81.5 \%$ & 0.624 \\
\hline $\mathbf{7}$ & Plagiarism-detecting softwares used & $18.8 \%$ & $14.6 \%$ & $20 \%$ & $17.7 \%$ & 0.578 \\
\hline
\end{tabular}

*significance at $p<0.05$

The significant $[p<0.05]$ difference of the knowledge, attitude and practice regarding plagiarism was noted in between I \& III MDS as

well as II \& III MDS students with the maximum III MDS having its knowledge than I and II MDS.

Table5. Intergroup comparison of Knowledge, Attitude and Practice about Plagiarism in between I, II and III year MDS

\begin{tabular}{|l|l|l|l|l|}
\hline $\begin{array}{l}\text { Sr. } \\
\text { No }\end{array}$ & Knowledge, Attitude and Practice & $\begin{array}{l}\text { I vs II } \\
\text { MDS }\end{array}$ & $\begin{array}{l}\text { I vs III } \\
\text { MDS }\end{array}$ & $\begin{array}{l}\text { II vs III } \\
\text { MDS }\end{array}$ \\
\hline $\mathbf{1}$ & Know the meaning of the term "Plagiarism"? & 0.788 & $0.036^{*}$ & $0.020^{*}$ \\
\hline $\mathbf{2}$ & $\begin{array}{l}\text { Aware of mandatory DCI points through scientific publications in } \\
\text { academics }\end{array}$ & 0.829 & 0.112 & $0.012^{*}$ \\
\hline $\mathbf{3}$ & Plagiarism is an act of academic malpractice & 0.297 & 0.109 & 0.494 \\
\hline $\mathbf{4}$ & Plagiarism is a punishable offence & 0.532 & 0.101 & $0.001^{*}$ \\
\hline $\mathbf{5}$ & Softwares available to check plagiarism & 0.412 & 0.310 & $0.008^{*}$ \\
\hline $\mathbf{6}$ & Has adverse effect on the health of the community & $0.014^{*}$ & 0.798 & $0.001^{*}$ \\
\hline $\mathbf{7}$ & Lack of faculty members to address this issue & 0.297 & 0.249 & 0.882 \\
\hline $\mathbf{8}$ & Think plagiarism as sometimes a necessity & 0.052 & 0.054 & 0.806 \\
\hline $\mathbf{9}$ & Think that short deadlines in academics as major impetus & $0.01^{*}$ & $0.01^{*}$ & 0.792 \\
\hline $\mathbf{1 0}$ & Regulations should be laid down against plagiarism & 0.149 & 0.198 & 0.691 \\
\hline $\mathbf{1 1}$ & Published your scientific article & 0.119 & $0.01^{*}$ & $0.01^{*}$ \\
\hline $\mathbf{1 2}$ & Practiced plagiarism & 0.206 & 0.183 & 0.943 \\
\hline $\mathbf{1 3}$ & Plagiarizing because you haven't been caught yet & $0.01 *$ & 0.288 & $0.01^{*}$ \\
\hline $\mathbf{1 4}$ & Studying in a plagiarism-free environment & 0.130 & 0.143 & 0.894 \\
\hline $\mathbf{1 5}$ & Staff encourage plagiarism & 0.472 & 0.782 & 0.132 \\
\hline $\mathbf{1 6}$ & Plagiarism hurt your inner conscience & 0.419 & 0.332 & 0.818 \\
\hline $\mathbf{1 7}$ & Plagiarism-detecting softwares used & 0.575 & 0.875 & 0.300 \\
\hline
\end{tabular}

Kruskal Wallis Test, * significance at $p<0.05$

\section{DISCUSSION}

Scientific progress depends on the free dissemination of original thinking and research[7].But in the today's "publish or perish" scenario among academicians and research scholars, everybody is in a hurry to publish their articles by hook or by crook and hence, they succumb to scientific misconduct such as falsification, fabrication and plagiarism. Plagiarism has become the easy escape-way for academicians and clinicians as well. Failure to recognize the quality of scientific literature is serious than the number of publications. Postgraduate students in healthcare are the torch-bearers of future research. Hence, they should be sincere and honest in their search for scientific truth. Plagiarism can also adversely affect the health of patients because patients are benefitted only from high standards of evidence based practice. By prescribing erroneous treatment to an individual, only single patient is affected; but by presenting incorrect data or transcripts, the whole scientific universe subjected to that particular treatment modality, can be affected. Although both scenarios are highly undesirable, one can assume the magnitude of the effect of the later [8].Postgraduate students are turning to plagiarism for easy and quick academic progress. Hence, there arises an urgent need to assess the mindsets of students towards plagiarism to curb this serious plague of "literary theft".

There are a number of contributing factors or the so called driving forces for individuals and students getting inclined towards this malpractice. The most important is lack of value-based education in early education curriculum. The modern education system lacks the intent to inculcate integrity and honesty in the young minds. Another important reason is the vast ocean of knowledge and information available on internet by the mere use of 
fingertips. This has facilitated the easy and convenient use of "copy and paste" techniques to portray another's ideas or work as one's own. Another important contributing factor can be the pressure within oneself as well as peer and societal pressure to increase the credit associated with one's name. Also, the lack of fluency and finesse in English linguistic skills and lack of training, skills and expertise about writing manuscripts go hand in hand to increase the prevalence of plagiarism. Time constraints for submissions \& meeting dead-lines can also lead to slightly modified or not-so-modified text from here and there, projected as one's own. Lack of proper regulations against this academic menace and lack of awareness amongst authors regarding the software available to detect plagiarism play a focal part in increasing the prevalence of plagiarism.

The present study targeted MDS students across Maharashtra to assess their perception towards the ill-practice of plagiarism. They were asked to respond to online links on survey monkey. com. Thus, the present study used the mode which greatly appealed to students and was easy to respond, fast and convenient. This mode was purposefully selected over the conventional paper and pencil survey to ensure better response rate and to reach out to greater number of MDS students easily in a shorter period of time. Also the anonymous responses on this website ensured blinding which decreased bias in the study.

Since the data obtained was a qualitative data, Pearson's Chi Square Test and Fischer Exact Test were used. The present study showed that III MDS students had more knowledge about plagiarism as compared to I and II MDS students in 5 out of 6 knowledge-related questions. This can be justified by the more exposure of III MDS students to the world of publications as compared to I and II MDS students. One contradictory finding here is about the knowledge regarding plagiarism having adverse effect on the health of the community where I MDS students had more knowledge.

The present study showed that there was no significant difference in the attitudes towards plagiarism amongst I, II and III MDS students except for the perception that short deadlines in academics are a major impetus to plagiarism, which was more prevalent in III MDS students, again obviously due to more exposure to the 'publish or perish' environment. Most of the students [54\%] reported inadequate knowledge of the art of writing the manuscript as a reason for committing plagiarism. This issue needs to be addressed by individual institutions and necessary measures should be taken by institution to incorporate such training skills in postgraduate academic curriculum.

More number of III MDS students had got their scientific article published as compared to I and II MDS students. This might be attributed to more amount of time spent by III MDS students on research as compared to I \& II MDS students. More number of II MDS students conceded to the fact that they were plagiarizing because they haven't been caught yet. Apart from this, there was no significant difference in the practices towards plagiarism between I, II and III MDS students.

Thus, it can be said that though III MDS students had more knowledge about plagiarism; however there was no significant difference in the attitude and practices of plagiarism among I, II and III MDS students. This shows the indifference and casual attitude of MDS students towards plagiarism.

The literature search revealed very few studies on perception of plagiarism on dental and medical students. There was not a single study which compared perception of plagiarism amongst MDS postgraduate students. The results of the present study are contradictory to that conducted by Ford and Hughes [9] where no postgraduate dental students identified plagiarism as an issue and the majority of students and staff supported the mandatory use of Turnitin in all courses with the exception of postgraduate students, many of whom [44\%] were still undecided on the value of this practice. According to study conducted by Singh et al. On dental professionals most of the dental professionals know about plagiarism and they believe that pressure to publish was a major reason along with several others, which accounts for more and more indulgence in plagiarism [10]. According to study conducted by Gomez et al. [3] on dental postgraduate 
students and faculty members, $31 \%$ of postgraduate students and $25 \%$ of faculty members agreed to the statement that short deadlines give them the right to plagiarize a bit, but $41 \%$ of postgraduate students and $47 \%$ of faculty members disagreed for the same and $51 \%$ of postgraduate students and $41 \%$ of faculty members disagreed for the statement that they are working or studying in a plagiarismfree environment. This is in contradiction to the present study where $82.3 \%$ of MDS students agreed that short deadlines in academics are a major impetus to the practice of plagiarism and only $31.5 \%$ students said that they are studying in a plagiarism free environment.

Our finding showed that less than half of students [49.2\%] agreed that plagiarism is a punishable offense; $54.8 \%$ students thought that plagiarism is sometimes a necessity; and hence knowingly practiced plagiarism and 21.8\% plagiarized because they hadn't been caught. These observations highlight serious concerns of the researchers' behavior towards plagiarism. Hence it is necessary to take sufficient efforts to counter these behaviors of researchers' through promoting the education of bioethics and establishing research integrity cell to check for the plagiarism offenses. Along with advances in science, in recent decades, plagiarism has crept up to dilute the worth of research papers [11]. Hence, serious and prompt steps need to be taken to raise the standards of scientific research and publications because it is on these that the future and advances of mankind depend on.

\section{CONCLUSION}

Honesty, truthfulness, integrity, dedication and determination are the pillars of genuine scientific research. But Plagiarism is a major issue that threatens our search for truth in science. "Scientific research has been overtaken by careerism and a management culture to the detriment of originality and discovery", laments Peter A. Lawrence in "The politics of Publication" [12]. Hence, steps need to be taken urgently to curb this scientific menace. Google and plagiarism detecting softwares obviously doing their bit to cease this ever-increasing epidemic of plagiarism; but we, as dental professionals, should also shoulder this responsibility and do our bit by adapting value- based scientific research and practice of publications. We should understand the thin line of difference between searching and researching. Interventions such as workshops and Continuing Dental Education programs need to be conducted to raise the awareness about plagiarism amongst students and also for faculty members so that they can educate their students about it. Combined efforts on the part of author, peer reviewers, editorial boards, software developers, students and faculty members are the only means to curb this literary theft.

\section{ACKNOWLEDGEMENT}

The authors are grateful to Dr Prashant Patil, Assistant Professor, Bhausaheb Hire Government Medical College, Dhule for carrying out the required statistical analysis. The authors also extend their heartfelt gratitude towards the MDS students who spared their precious time to respond to the online links.

\section{REFERENCES}

[1] Satyanarayana K. Plagiarism: a scourge afflicting the Indian science. Indian J Med Res March 2010; 131:373-6.

[2] Das N, Panjabi M. Plagiarism: Why is it such a big issue for medical writers? Perspect Clin Res 2011 Apr-Jun; 2[2]: 67-71.

[3] Gomez MSS, Nagesh L, Sujatha BK. Assessment of the attitude towards Plagiarism among dental postgraduate students and faculty members in Bapuji Dental College and Hospital, Davangere - A cross sectional survey. IOSR Journal of Dental and Medical Sciences2014; 13[5]: 1-6.

[4] Berlinck RGS. The academic plagiarism and its punishments- a review. Rev Bras Farmacogn Braz J Pharmacogn2011; 21[3]: 365-72.

[5] Subba Reddy VV. Greetings from Davangere, Karnataka, India: Searching versus researching.J Indian Soc Pedod Prev Dent 2011 Jan-Mar; 29[1]: 1.

[6] Sriganesh V, Iyer P. Plagiarism and medical writing. Indian J Radiol Imaging2007; 17[3]: 146-7.

[7] Rathod SD. Combating plagiarism: a shared responsibility. Indian JMed Ethics 2010; 7[3]:173-5.

[8] Sharma BB, Singh V. Ethics in writing: Learning to stay away from plagiarism and scientific misconduct. Lung India 2011; 28: 148-50. 
[9] Ford PJ, Hughes C. Academic integrity and plagiarism: perceptions and experience of staff and students in a school of dentistry: A situational analysis of staff and student perspectives. Eur J Dent Educ 2012; 16: e180e186.

[10] Singh HP, Guram N. Knowledge and Attitude of Dental Professionals of North India Toward
Plagiarism. N Am J Med Sci 2014 Jan; 6[1]: 6-11.

[11] Batra M, Gupta M, Rajwar YC. Plagiarism: A Trojan in Medical Research Writing. Sch J App Med Sci 2014; 2[1C]:266-8.

[12] Sapatnekar SM. Plagiarism. J Assoc Physicians India2004; 52:527-30.

Citation: Deshmukh Manjiri, Dodamani Arun, Karibasappa GN, Khairnar Mahesh, Naik Rahul. Knowledge, Attitude and Practice of Postgraduate Dental Students Towards Plagiarism in Maharashtra State, India: A Cross-Sectional Survey. ARC Journal of Dental science. 2017; 2(3): 1-7. doi:dx.doi.org/10.20431/24560030.0203001 .

Copyright: (c) 2017 Authors. This is an open-access article distributed under the terms of the Creative Commons Attribution License, which permits unrestricted use, distribution, and reproduction in any medium, provided the original author and source are credited. 